\title{
REGENERAÇÃO NATURAL EM SUB-BOSQUE DE Corymbia citriodora NO NOROESTE DO ESTADO DO PARANÁ
}

\author{
Edilson Batista de Oliveira ${ }^{1}$, Letícia Penno de Sousa $^{2}$, Maria Izabel Radomski ${ }^{3}$ \\ ${ }^{1}$ Eng. Agrônomo, Dr., EMBRAPA Florestas, Colombo, PR, Brasil - edilson@cnpf.embrapa.br \\ ${ }^{2}$ Eng ${ }^{a}$ Florestal, M.Sc., EMBRAPA Florestas, Colombo, PR, Brasil - leticia@cnpf.embrapa.br \\ ${ }^{3}$ Eng $^{\mathrm{a}}$ Agrônoma, Dra ., EMBRAPA Florestas, Colombo, PR, Brasil - izabel@ cnpf.embrapa.br
}

Recebido para publicação: 16/04/2009 - Aceito para publicação: 14/04/2010

\begin{abstract}
Resumo
O desenvolvimento de espécies nativas plantadas em consórcio com eucaliptos, ou regeneradas naturalmente em povoamentos dessas espécies, vem sendo acompanhado em propriedades rurais do noroeste do estado do Paraná. Esses sistemas se destacam por constituir uma opção para a recuperação da cobertura florestal em ambientes degradados pela pecuária e agricultura intensivas, propiciando rentabilidade econômica, com possibilidade de atender a legislação ambiental para Reserva Legal. O presente trabalho visa conhecer o potencial de recomposição da vegetação nativa em sub-bosque de Corymbia citriodora, nas condições ambientais e de uso do solo daquela região. Assim, foi avaliada a composição florística e a estrutura da vegetação formada sob a rebrota de um povoamento dessa espécie, situado em São Pedro do Paraná (PR). Foram encontradas cinquenta e três espécies oriundas de regeneração natural numa densidade de 4.725 plantas por hectare. As plantas, identificadas até o nível de espécie, foram enquadradas segundo seu grupo ecológico e/ou usos potenciais. Foram observados parâmetros estruturais que mostraram o elevado potencial de regeneração natural e crescimento da vegetação em sub-bosque de $C$. citriodora, indicando que, com manejo adequado, essa espécie pode ser usada como uma facilitadora para fins de recomposição de vegetação nativa.

Palavras-chave: Regeneração natural; plantação florestal; composição florística.
\end{abstract}

\begin{abstract}
Natural regeneration in understory of Corymbia citriodora plantation, in north-west of Paraná state, Brazil. Natural regeneration in eucalyptus stands, as well as forest plantations that combine eucalyptus and native species, have been monitored in rural areas in the north-west of Paraná State, Brazil. Such forest systems involving eucalyptus represent an alternative for forest recovery and regeneration in areas degraded by livestock and intensive agriculture. Furthermore, such plantations offer new economic opportunities for landowners while providing incentives for their compliance with environmental regulations for saving a minimum amount of forested land (Reserva Legal). This study aims to understand the potential of natural vegetation recovery in the understory of Corymbia citriodora stands, due to the context of current environment and land use in the region. Thus, it evaluates floristic composition and vegetation structure in the understory re-growth within such plantation stands, in São Pedro do Paraná (Paraná State). As result, it identified 53 species from natural regeneration at a density of 4725 plants per hectare. Such plants, identified at the species level, were organized accordingly to their ecological group and/or potential uses. The observed structural parameters pointed to a high potential for natural regeneration and growth of vegetation in the understory of $C$. citriodora, which reveals that, with appropriated management, these species could be used to make native restoration vegetation easer in the region. Keywords: Natural regeneration; forest plantations; floristic composition.
\end{abstract}

\section{INTRODUÇÃO}

A mesorregião Noroeste do Paraná caracteriza-se por apresentar uma situação ambiental das mais degradadas no estado, sendo esse quadro consequência direta do intenso desmatamento e da forma inadequada do uso atual e anterior da terra, aliados à fragilidade edáfica imposta pelo Arenito Caiuá. Sua ocupação, iniciada a partir da colonização regional, em meados do século passado, deu-se com a implantação da cultura do café e posteriormente com culturas anuais, impondo desde então problemas

FLORESTA, Curitiba, PR, v. 41, n. 2, p. 377-386, abr./jun. 2011.

Oliveira, E. B. de; Sousa, L. P. de; Radomski, M. I. 
ambientais, por se basearem em modelos de terraceamento ineficientes no combate à erosão para essa região em particular (FIDALSKI, 1997). Dados do Instituto Paranaense de Desenvolvimento Econômico e Social (IPARDES) (2004) indicam que essa mesorregião possui apenas $4 \%$ das florestas originais, sendo que $84 \%$ desse percentual estão protegidos sob a forma de Unidades de Conservação de Proteção Integral.

A cobertura vegetal nativa da região, constituída originalmente pela Floresta Estacional Semidecidual, determinou a ocorrência de altos teores de matéria orgânica no perfil da camada arável dos solos, assegurando uma boa fertilidade aparente. Entretanto, após os desmatamentos e o uso intensivo, estes se tornaram depauperados em curto prazo, pelo fato de serem oriundos de material geológico pobre originado da formação Arenito Caiuá, o que imprime grande vulnerabilidade à erosão hídrica e eólica, além de possuir baixas reservas minerais (MUZILLI, 1996).

Diante do quadro de degradação relatado, fica evidente a forte necessidade de recuperação ambiental, tanto sob o ponto de vista das Áreas de Preservação Permanente como das de Reserva Legal (RL). No que se refere às RLs, no noroeste do estado do Paraná, através de parceria realizada entre o governo estadual, sob as secretarias de Planejamento, de Meio Ambiente e Recursos Hídricos e de Abastecimento e Agricultura e a Embrapa Florestas, estão sendo realizados plantios de espécies arbóreas nativas em consórcio com espécies de eucalipto adaptadas à região. A proposta é o estabelecimento de plantios e do manejo da vegetação nativa e exótica, visando reconstituir a cobertura florestal e formar bancos de germoplasma de espécies nativas. Nesses sistemas, a espécie exótica é utilizada como uma secundária inicial de matriz e recebe desbastes sistemáticos até ser excluída totalmente pela colheita final. Esse manejo possibilita renda aos produtores e libera espaço para as espécies nativas crescerem. É válido ressaltar que a possibilidade de recomposição da RL com o plantio de espécies exóticas em caráter temporário, tendo como propósito estabelecer condições favoráveis à restauração do ecossistema original, consta no Código Florestal Brasileiro e foi apoiada na Resolução da SEMA n ${ }^{\circ}$ 045/2008.

Os plantios florestais com espécies exóticas podem ser analisados como uma alternativa para a conservação e a regeneração dos ecossistemas naturais (ÁVILA et al., 2007). Em estudo realizado no município de Santa Maria, RS, esses autores observaram uma elevada diversidade florística na regeneração em sub-bosque de Eucalyptus camaldulensis (25 espécies, pertencentes a 25 gêneros, distribuídos em 18 famílias), indicando que povoamentos com espécies exóticas podem atuar como abrigo para diversas espécies vegetais.

Outros estudos também mostram que algumas espécies de eucalipto podem ser usadas com sucesso na recomposição da vegetação, atuando como facilitadoras para a regeneração de espécies nativas (SILVA JÚNIOR et al., 1995; GELDENHUIS, 1997; FEYERA et al., 2002; SARTORI et al., 2002; SAPORETTI JR. et al., 2003; ÁVILA et al., 2007; FERREIRA et al., 2007), quando a finalidade da área for econômica e ambiental simultaneamente, como no caso das Reservas Legais.

Espécies de eucalipto possuem crescimento rápido e alta resistência ao déficit hídrico. Além disso, os baixos custos de plantio e a baixa exigência qualitativa quanto ao solo as tornam muito apropriadas para a formação de povoamentos florestais. Numa condição de Reserva Legal, além de ser fonte de recursos, tais características propiciam o estabelecimento rápido de uma cobertura florestal, reduzindo a erosão superficial e favorecendo a instalação de espécies tolerantes à sombra e, em geral, de uma comunidade vegetal mais diversa. Economicamente, espécies de eucalipto possuem importância na produção de papel, na indústria farmacêutica, na de cosméticos, na de artigos de limpeza e de perfumaria, na construção civil e como material combustível (SCHNEIDER, 2003).

Esta pesquisa foi baseada na hipótese de que o consórcio de espécies nativas regeneradas naturalmente em plantios de eucaliptos, além de possibilitar a recomposição da vegetação nativa, é uma maneira de viabilizar a diversificação de renda para o agricultor.

O objetivo do trabalho foi avaliar a composição florística e a estrutura da vegetação advinda de regeneração natural formada sob a rebrota de uma plantação de Corymbia citriodora situada no município de São Pedro do Paraná (PR). Buscou-se ainda identificar o potencial da capacidade de regeneração da vegetação nativa sob espécies de eucalipto nas condições ambientais e de uso do solo próprios da região, para fins de recomposição e manejo da vegetação de Reserva Legal na região noroeste do estado do Paraná. 


\section{MATERIAL E MÉTODOS}

\section{Caracterização regional}

A mesorregião Noroeste está localizada no Terceiro Planalto ou Planalto do Trapp do Paraná, o qual é constituído, em sua maior extensão, por derrames basálticos. A conformação de sua paisagem é bastante uniforme, em relevo suavemente ondulado, a uma altitude média de $300 \mathrm{~m}$ acima do nível do mar. Nesse planalto encontra-se a formação Arenito Caiuá, de origem eólica, que se depositou sobre o derrame do Trapp e deu origem a solos com baixos teores de argila, textura predominantemente arenosa e, consequentemente, baixa capacidade de retenção de água, com moderada a baixa fertilidade e facilmente sujeitos à erosão (MUZILLI, 1996).

O clima da região caracteriza-se pelo tipo Cfa, caracterizado pela temperatura média no mês mais frio inferior a $18{ }^{\circ} \mathrm{C}$ e temperatura média no mês mais quente superior a $22{ }^{\circ} \mathrm{C}$, verões quentes, geadas pouco frequentes, inverno seco, com concentração das chuvas nos meses de verão, contudo sem período seco definido (INSTITUTO AGRONÔMICO DO PARANÁ (IAPAR), 2008).

A cobertura florestal original era composta pela Floresta Estacional Semidecidual Submontana (entre 50 e 500 metros de altitude), onde se destacavam a peroba (Aspidosperma polyneurum), o pau-marfim (Balfourodendron riedelianum), o alecrim (Holocalyx balansae) e a palmeira "juçara" (Euterpe edulis) (INSTITUTO BRASILEIRO DE GEOGRAFIA E ESTATÍSTICA (IBGE), 1991; PARANÁ, 1995).

\section{Coleta de dados}

O trabalho foi realizado no município de São Pedro do Paraná, em uma propriedade rural cujas atividades econômicas são baseadas na produção de grãos e de gado de corte em sistema extensivo. Nessa propriedade, em uma área de três hectares ocupada originalmente com pastagem de braquiária (Brachiaria spp.), foi efetuado em 1994 um plantio do eucalipto citriodora (Corymbia citriodora), no espaçamento de $3 \mathrm{~m} \times 2 \mathrm{~m}$. Após o corte final efetuado em 2001, o local foi abandonado. A área, com $8 \%$ de declividade, encontra-se próxima a uma faixa de floresta ciliar situada no final de pendente.

Para o estudo da vegetação, a área com rebrota de eucalipto com idade de sete anos foi dividida em três parcelas de $10 \times 20 \mathrm{~m}$, locadas cada uma delas nos terços superior (parcela 1), médio (parcela 2) e inferior (parcela 3) da pendente, em sentido perpendicular a esta, buscando-se a homogeneidade em relação aos solos. Em cada parcela foi efetuada a mensuração dos indivíduos arbóreos e arbustivos com altura superior a $1,0 \mathrm{~m}$ e/ou com CAP $\geq 3 \mathrm{~cm}$, incluindo-se, portanto, todos os estratos da floresta.

O enquadramento das espécies nas famílias botânicas foi baseado no Sistema de Classificação de Cronquist (1981). Os dados de altura e diâmetro foram submetidos a análise fitossociológica, tendo-se estimado os parâmetros Densidade Absoluta e Relativa (\%), Dominância Absoluta e Relativa e Valor de Cobertura, sendo:

Densidade Absoluta $(D A)=n_{i} /$ ha;

Densidade relativa $(\mathrm{DR})=100 .\left(\mathrm{n}_{\mathrm{i}} / \mathrm{ha}\right) /(\mathrm{N} / \mathrm{ha})$, em que $\mathrm{n}$ é o número de árvores de cada espécie e $\mathrm{N}$ número total de árvores;

Dominância Absoluta $(\mathrm{DoA})=$ soma das áreas transversais dos indivíduos de uma mesma espécie, por unidade de área;

Dominância Relativa $(\mathrm{DoR})=$ \% da área basal de cada espécie em relação à área basal total de todas as árvores de todas as espécies, por unidade de área;

Valor de Cobertura $(\mathrm{VC})=$ Soma $(\mathrm{DR}+$ DoR. $)$.

Além do cálculo dos parâmetros fitossociológicos, as espécies com identificação completa foram enquadradas segundo seu grupo ecológico e/ou usos potenciais.

\section{RESULTADOS E DISCUSSÃO}

$\mathrm{Na}$ área de estudo foram encontradas 53 espécies distintas (Tabela 1), das quais apenas uma de porte arbustivo (Piper glabatum) e 31 identificadas até o nível de espécie. As espécies estão distribuídas em 21 famílias, sendo que seis espécies são exóticas na formação da Floresta Estacional Semidecidual (Tabela 2). A estimativa do número total de indivíduos regenerados por hectare é de 4.721 . O número de rebrotas de $C$. citriodora foi estimado em 733, com altura média de 15 metros. 
Tabela 1. Parâmetros fitossociológicos da regeneração natural em sub-bosque de Corymbia citriodora.

Table 1. Phytosociological parameters of natural regeneration on Corymbia citriodora understorey.

\begin{tabular}{|c|c|c|c|c|c|c|c|c|c|}
\hline Família & Nome científico & DA & DR & DoA & DoR & VC & Parc. & $\begin{array}{l}\text { DAP } \\
\text { máx. } \\
\text { (cm) }\end{array}$ & $\begin{array}{c}\mathbf{H} \\
\text { máx. } \\
\text { (m) }\end{array}$ \\
\hline $\begin{array}{l}\text { *Fabaceae- } \\
\text { Caesalpinoidea }\end{array}$ & Pterogyne nitens Tul. & 992 & 20,99 & 1,2566 & 19,75 & 40,74 & 123 & 12,7 & 18,0 \\
\hline Sapindaceae & $\begin{array}{l}\text { Allophylus edulis (St.-Hil.) } \\
\text { Radlk }\end{array}$ & 908 & 19,22 & 0,2467 & 3,88 & 23,10 & 123 & 2,9 & 4,0 \\
\hline $\begin{array}{l}\text { Fabaceae- } \\
\text { Mimosoidea }\end{array}$ & $\begin{array}{l}\text { Parapiptadenia rigida } \\
\text { (Benth.) Bren. }\end{array}$ & 400 & 8,47 & 0,3096 & 4,87 & 33 & 123 & 13,4 & 15,0 \\
\hline Apocynaceae & $\begin{array}{l}\text { Peschieria fuchsiaefolia } \\
\text { (A. DC.) Miers. }\end{array}$ & 267 & 5,64 & 0,2667 & 4,19 & 9,84 & 123 & 9,5 & 7,0 \\
\hline $\begin{array}{l}\text { Fabaceae- } \\
\text { Faboidea }\end{array}$ & $\begin{array}{l}\text { Lonchocarpus } \\
\text { muehlbergianus Hassler }\end{array}$ & 233 & 4,94 & 0,4869 & 7,65 & 12,59 & 123 & 7,0 & 11,0 \\
\hline $\begin{array}{l}\text { Fabaceae- } \\
\text { Mimosoidea }\end{array}$ & $\begin{array}{l}\text { Albizia hasslerii (Chodat) } \\
\text { Burkart }\end{array}$ & 158 & 3,35 & 0,0684 & 1,08 & 2,31 & 123 & 6,7 & 5,5 \\
\hline Myrtaceae & Psidium guajava $\mathrm{L} . * *$ & 150 & 3,17 & 0,0423 & 0,66 & 3,84 & 123 & .5 & 4,0 \\
\hline Arecaceae & $\begin{array}{l}\text { Acrocomia aculeata (Jacq.) } \\
\text { Lodd. }\end{array}$ & 142 & 3,00 & 0,6783 & 10,66 & 1. & 123 & 21,6 & 6,0 \\
\hline Flacourtiaceae & Casearia sylvestris $\mathrm{Sw}$. & 142 & 3,00 & 0,4525 & 7,11 & 10,11 & 123 & 8,5 & 4,0 \\
\hline Euphorbiaceae & $\begin{array}{l}\text { Alchornea triplinervia } \\
\text { (Spreng.) M. Arg. }\end{array}$ & 117 & 2,47 & 0,9888 & 15,54 & 18,01 & 123 & 13,1 & 8,0 \\
\hline $\begin{array}{l}\text { Fabaceae- } \\
\text { Faboidea }\end{array}$ & Lonchocarpus sp. & 117 & 2,47 & 0,1032 & 1,62 & 4,09 & 123 & 6,1 & 13,5 \\
\hline Cecropiaceae & $\begin{array}{l}\text { Cecropia glaziovii } \\
\text { Snethlage }\end{array}$ & 92 & 1,94 & 0,7476 & 11,75 & 13,69 & 123 & 20,7 & 12,0 \\
\hline Lauraceae & $\begin{array}{l}\text { nceolata } \mathrm{Nee} \\
\text { ia }\end{array}$ & 92 &, 94 & 24 & 130 & 4 & 123 & 3,8 & 4,0 \\
\hline Euphorbiaceae & $\begin{array}{l}\text { comme } \\
\text { Smith }\end{array}$ & 92 & 1,94 & 0,0494 & 0,78 & 2,72 & 23 & 6,4 & 4,0 \\
\hline $\begin{array}{l}\text { Fabaceae- } \\
\text { Caesalpinoidea }\end{array}$ & $\begin{array}{l}\text { Peltophort } \\
\text { (Spreng.) }\end{array}$ & 83 & 1,76 & 0,0360 & 0,57 & 2,33 & 123 & 5,9 & 5,0 \\
\hline Rosaceae & Citrus & 58 & 23 & 0 & 063 & 1 & 123 & 41 & 3,0 \\
\hline Myrtaceae & Myrtac & 58 & 1,23 & 77 & 0 , & & & & 2,0 \\
\hline Thymelinaceae & $\mathrm{T}$ & 50 & 106 & 0,1078 & 169 & & 12 & 10,2 & 8,0 \\
\hline & E & & & & & & & & 1,5 \\
\hline Lauraceae & $L c$ & 42 & 0,88 & 0,0300 & 0,47 & 1,35 & 123 & 0 & 3,0 \\
\hline Sapc & $\begin{array}{l}C l \\
g o \\
\mathrm{Ei}\end{array}$ & 33 & 71 & 88 & 0 & 1 & 1 & 8 & 4,0 \\
\hline Kosc & Citrus & 5 & & 0,00 & 0 , & & & & 2,0 \\
\hline & $R c$ & 33 & & & & & & & 3,0 \\
\hline Indeterminada & Indet. 5 & 25 & 0,53 & 0,0224 & 0,35 & 0,88 & 23 & 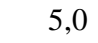 & 3,5 \\
\hline & Luehe & 25 & 0,53 & 0,0450 & 0,7 & 1,24 & 123 & & 3,0 \\
\hline Myrtaceae & & 25 & 0,53 & 0,0083 & 0,13 & 0,66 & ( & , 2 & 3,0 \\
\hline 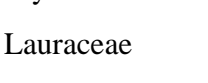 & $\begin{array}{l}\text { Ocote } \\
\text { (Meis }\end{array}$ & 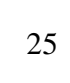 & 0,53 & 0,0157 & 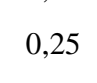 & 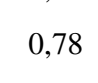 & 2 & 0 & , \\
\hline Boraginaceae & Patagonula americana $\mathrm{L}$. & 25 & 0,53 & 0,0314 & 0,49 & 1,02 & 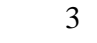 & 5,1 & 4,0 \\
\hline e & $\begin{array}{l}\text { Siparuna apiosyce (Mart } \\
\text { A. DC. }\end{array}$ & 25 & 53 & 77 & 0,12 & 5 & 23 & 2 & 5 \\
\hline Nycta & entosa Clos & 1 & & & & & & & 3,0 \\
\hline & Myrtaceae 2 & 1. & & & 0, & & & & 1,0 \\
\hline & & 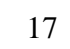 & & & 0, & & 2 & & 1,0 \\
\hline & & 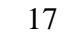 & & & 0 , & & 3 & & 1,5 \\
\hline & & 17 & & 0,00 & 0,0 & 0,3 & 2 & 0,0 & 2,0 \\
\hline Flacourtiaceae & Casearia obliqua Spreng. & 8 & 0,18 & 0,0000 & 0,00 & 0,18 & 1 & 0,0 & 2,0 \\
\hline
\end{tabular}




\begin{tabular}{|c|c|c|c|c|c|c|c|c|c|}
\hline Lauraceae & $\begin{array}{l}\text { Endlicheria paniculata } \\
\text { Spreng.) J. F. Macbr. }\end{array}$ & 8 & 0,18 & 0,0000 & 0,00 & 0,18 & 3 & 0,0 & 0,2 \\
\hline Rosaceae & Citrus reticulata Blanco** & 8 & 0,18 & 0,0008 & 0,01 & 0,19 & 3 & 1,0 & 2,0 \\
\hline Lauraceae & $\begin{array}{l}\text { Cryptocarya } \\
\text { aschersoniana } \mathrm{Mez}\end{array}$ & 8 & 0,18 & 0,0000 & 0,00 & 0,18 & 2 & 0,0 & 1,0 \\
\hline Sapindaceae & $\begin{array}{l}\text { Matayba elaeagnoides } \\
\text { Radlk }\end{array}$ & 8 & 0,18 & 0,0065 & 0,10 & 0,28 & 2 & 2,2 & 3,5 \\
\hline Meliaceae & Melia azedarach L.** & 8 & 0,18 & 0,0258 & 0,41 & 0,58 & 1 & 9,5 & 10,0 \\
\hline Myrtaceae & Myrtaceae 6 & 8 & 0,18 & 0,0000 & 0,00 & 0,18 & 2 & 0,0 & 3,0 \\
\hline Myrtaceae & Myrtaceae 7 & 8 & 0,18 & 0,0000 & 0,00 & 0,18 & 2 & 0,0 & 0,7 \\
\hline Lauraceae & $\begin{array}{l}\text { Nectandra megapotamica } \\
\text { (Spreng.) Mez }\end{array}$ & 8 & 0,18 & 0,0063 & 0,10 & 0,28 & 3 & 1,9 & 2,0 \\
\hline Piperaceae & Piper glabratum Kunth & 8 & 0,18 & 0,0037 & 0,06 & 0,23 & 2 & 1,5 & 2,5 \\
\hline Annonaceae & $\begin{array}{l}\text { Rollinia sylvatica (St.-Hil.) } \\
\text { Mart. }\end{array}$ & 8 & 0,18 & 0,0081 & 0,13 & 0,30 & 1 & 2,6 & 3,0 \\
\hline Rubiaceae & Rubiaceae 1 & 8 & 0,18 & 0,0000 & 0,00 & 0,18 & 1 & 0,0 & 2,0 \\
\hline Rubiaceae & Rubiaceae 2 & 8 & 0,18 & 0,0000 & 0,00 & 0,18 & 3 & 0,0 & 1,5 \\
\hline Sapindaceae & Sapindaceae & 8 & 0,18 & 0,0423 & 0,66 & 0,84 & 2 & 4,8 & 4,0 \\
\hline Solanaceae & Solanaceae 1 & 8 & 0,18 & 0,0000 & 0,00 & 0,18 & 1 & 0,0 & 2,0 \\
\hline Solanaceae & Solanaceae 2 & 8 & 0,18 & 0,0000 & 0,00 & 0,18 & 2 & 0,0 & 2,0 \\
\hline Myrtaceae & $\begin{array}{l}\text { Syzygium cumini (L.) } \\
\text { Skeels** }\end{array}$ & 8 & 0,18 & 0,0110 & 0,17 & 0,35 & 3 & 4,1 & 4,0 \\
\hline Ulmaceae & $\begin{array}{l}\text { Trema micrantha }(\mathrm{L} .) \\
\text { Blume }\end{array}$ & 8 & 0,18 & 0,0321 & 0,50 & 0,68 & 3 & 7,0 & 4,0 \\
\hline Indeterminada & Indet. 1 & 8 & 0,18 & 0,0133 & 0,21 & 0,38 & 1 & 4,5 & 4,0 \\
\hline & $\begin{array}{l}\text { Densidade } \\
\text { Área basal }\end{array}$ & \multicolumn{8}{|c|}{$\begin{array}{l}4725 \text { ind./ha } \\
6,37 \mathrm{~m}^{2} / \mathrm{ha}\end{array}$} \\
\hline
\end{tabular}

DA: densidade absoluta; DR: densidade relativa; DoA: dominância absoluta $\left(\mathrm{m}^{2} / \mathrm{ha}\right)$ DoR: dominância relativa $\left(\mathrm{m}^{2} / \mathrm{ha}\right)$; VC: Valor de Cobertura; DAP: diâmetro à altura do peito; H: altura. Parc.: Parcela 1 - terço superior, parcela 2 - terço médio, parcela 3 - terço inferior. * A família Fabaceae, de acordo com o Sistema de Classificação de Cronquist (1988), refere-se ao conjunto das subfamílias Mimosoidea, Faboidea e Caesalpinoidea. **Espécies exóticas.

Das espécies amostradas, Pterogyne nitens foi a que apresentou maior densidade e dominância, seguida de Allophylus edulis e Parapiptadenia rigida. Já as famílias com maior número de representantes nativos foram Fabaceae (Leguminosae), Flacourtiaceae, Euphorbiaceae, Lauraceae e Sapindaceae.

Em função do número restrito de parcelas, não foi efetuado o cálculo da frequência. No entanto, observou-se que, das 53 espécies encontradas, apenas $19(35,8 \%)$ predominavam nas três parcelas, seis $(11,3 \%)$ ocorreram em duas parcelas e $28(52,8 \%)$ ocorreram em apenas uma das parcelas (Tabela 1$)$. Esse fato pode indicar uma possível influência do solo sobre a distribuição das espécies, já que as parcelas foram locadas em posições topográficas distintas, que podem refletir diferentes regimes hídricos do solo. Deve-se ressaltar que a distribuição de espécies também pode ser influenciada por outros fatores, como a síndrome de dispersão e a distância da fonte de propágulos do local analisado.

Das espécies nativas, as que apresentaram maiores valores em altura foram Pterogyne nitens, Parapiptadenia rigida, Lonchocarpus sp., Cecropia glaziovii e Lonchocarpus muehlbergianus. Já em relação ao diâmetro, as espécies com maiores valores foram Acrocomia aculeata, Cecropia glaziovii, Parapiptadenia rigida, Alchornea triplinervia e Pterogyne nitens. Esses valores não significam maiores incrementos anuais médios porque não se sabe quando cada indivíduo se estabeleceu.

À exceção de uma espécie (Chrysophyllum gonocarpum), todas as demais nativas são características de estágios iniciais da sucessão florestal, particularmente as espécies da família Fabaceae, desejáveis nos processos de restauração florestal em função da sua capacidade de melhoria do solo por meio da fixação de nitrogênio e deposição de serapilheira (CARPANEZZI; CARPANEZZI, 2006).

Nas figuras 1 e 2 encontram-se representadas, respectivamente, as alturas de todos os eucaliptos e dos demais indivíduos sem a presença de Corymbia citriodora. Comparando-se as figuras, observa-se que o eucalipto possui predominância de maiores alturas e uniformidade nas parcelas. Por outro lado, na regeneração natural predominam indivíduos no estrato de 2 a $4 \mathrm{~m}$ de altura (45\%), seguido do estrato de 1 a $2 \mathrm{~m}(27 \%), 4$ a $8 \mathrm{~m}(19,2 \%)$, até $1 \mathrm{~m}(6,3 \%)$ e maior que $8 \mathrm{~m}(2,5 \%)$. 


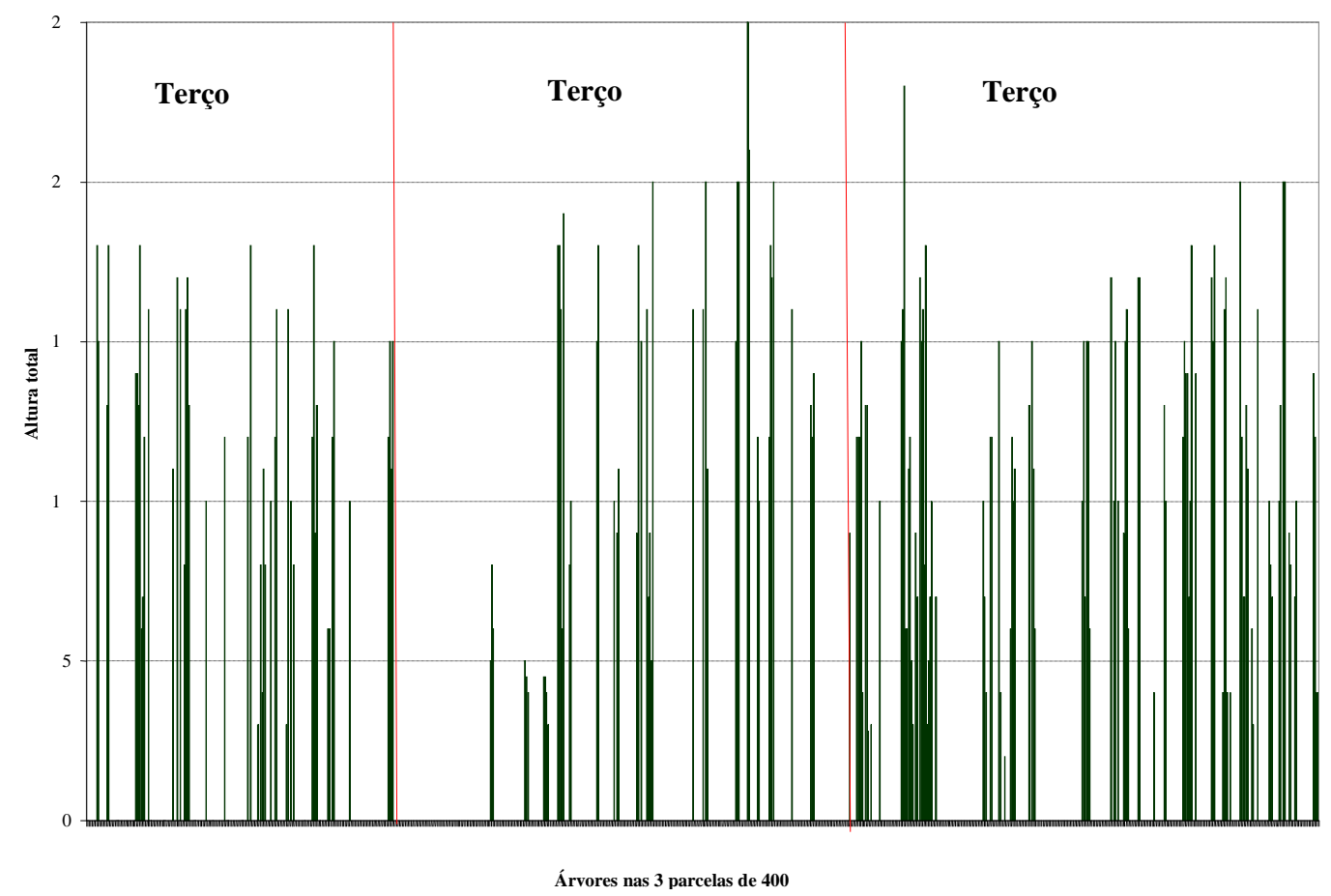

Figura 1. Distribuição das alturas das rebrotas dos eucaliptos nas 3 parcelas.

Figure 1. Heigth distribution of coppiced eucalyptus trees in the 3 plots.

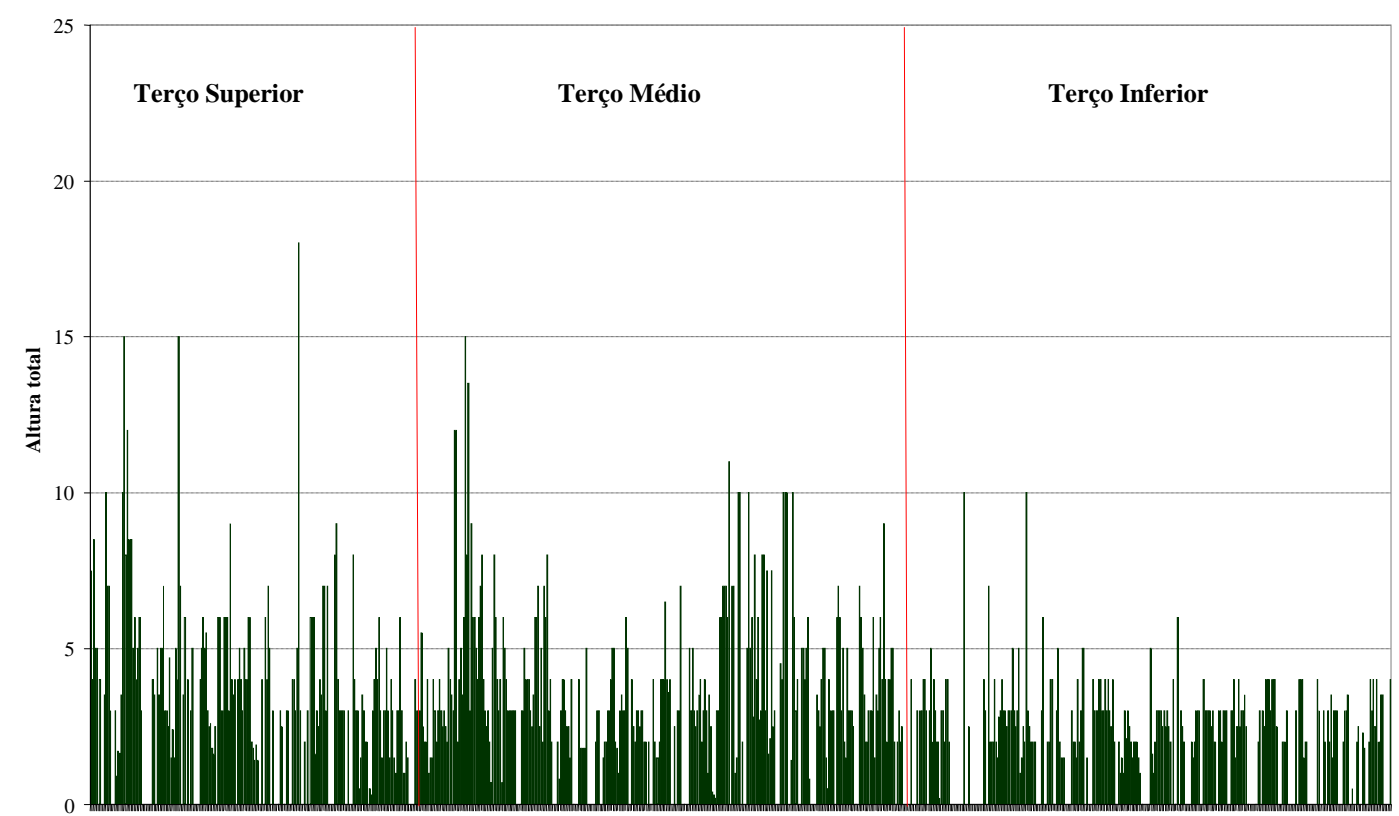

Figura 2. Distribuição das alturas das plantas regeneradas naturalmente nas 3 parcelas. Figure 2. Heigth distribution of natural regeneration plants in the 3 plots. 
Ainda no caso da regeneração, observaram-se diferenças na densidade e altura dos indivíduos em função da posição topográfica, sendo que no terço superior (parcela 1) foram encontrados menos indivíduos com maiores alturas, e mais indivíduos com menores alturas no terço inferior (parcela 3). Uma possível explicação para essas diferenças seria a ocorrência de capim-colonião nessa localização, dominando o ambiente, sobretudo inicialmente, quando havia mais luz, e em função do provável acúmulo de nutrientes e/ou umidade no solo, em decorrência da posição na paisagem. Essa competição inicial seria limitante para a entrada e o desenvolvimento de determinadas espécies da regeneração, mas numa fase posterior, quando o sombreamento se intensificou, a densidade foi aumentada pela diminuição da concorrência e pela proximidade ao remanescente próximo de vegetação ciliar. Portanto, o fato reforça a necessidade do controle de gramíneas competidoras, já que sua presença resulta no prejuízo ao estabelecimento e desenvolvimento da regeneração natural, particularmente de espécies de crescimento mais lento.

Dentre as espécies identificadas na regeneração com potencial madeireiro (Tabela 2), destacaram-se, com base nos dados de maior altura e DAP, Pterogyne nitens e Parapiptadenia rigida. Considerando todas as espécies amostradas na regeneração, a área apresentou um volume de produção de madeira de $18,6 \mathrm{~m}^{3} / \mathrm{ha}$, valor baixo se comparado à produção estimada para a rebrota do eucalipto citriodora, com cerca de $85 \mathrm{~m}^{3} /$ ha. Entretanto, deve-se levar em conta que a área não foi manejada, resultando em maior concorrência entre indivíduos, baixos diâmetros e, consequentemente, menor volume de madeira produzido.

Tabela 2. Espécies identificadas na regeneração natural em sub-bosque de Corymbia citriodora, grupo ecológico e usos potenciais.

Table 2. Identified species in natural regeneration of Corymbia citriodora understorey, ecological group and potential uses.

\begin{tabular}{|c|c|c|c|c|}
\hline Família & Nome científico & Nome comum & $\begin{array}{c}\text { Grupo } \\
\text { ecológico }\end{array}$ & Usos \\
\hline Annonaceae & Rollinia sylvatica (St.-Hil.) Mart. & Araticum-cagão & SI & $\begin{array}{l}\text { Al, Fa, Fi, } \\
\text { Mem }\end{array}$ \\
\hline Apocynaceae & Peschieria fuchsiaefolia (A. DC.) Miers. & Leiteiro & $\mathrm{P}$ & $\mathrm{C}, \mathrm{Fa}, \mathrm{L}, \mathrm{Min}$ \\
\hline Boraginaceae & Patagonula americana $\mathrm{L}$. & Guajuvira & SI & Artes, Mex \\
\hline Cecropiaceae & Cecropia glaziovii Snethlage & Embaúba & $\mathrm{P}$ & $\mathrm{Fa}, \mathrm{Fi}$ \\
\hline Euphorbiaceae & $\begin{array}{l}\text { Alchornea triplinervia (Spreng.) M. Arg. } \\
\text { Sebastiania commersoniana (Baillon) Smith \& } \\
\text { Dows }\end{array}$ & $\begin{array}{l}\text { Tapiá } \\
\text { Branquilho }\end{array}$ & $\begin{array}{l}\text { SI } \\
\text { SI }\end{array}$ & $\begin{array}{l}\text { Fa, Min } \\
\text { C, L, Min, } \\
\text { Fer, Mel }\end{array}$ \\
\hline Flacourtiaceae & $\begin{array}{l}\text { Banara tomentosa } \text { Clos } \\
\text { Casearia obliqua } \text { Spreng. } \\
\text { Casearia sylvestris } \mathrm{Sw} .\end{array}$ & $\begin{array}{l}\text { Guaçatunga } \\
\text { Guaçatunga } \\
\text { Cafezinho }\end{array}$ & $\begin{array}{l}\text { SI } \\
\text { SI } \\
\text { SI }\end{array}$ & $\begin{array}{l}\text { Fa, Mel } \\
\text { Fa, Mel } \\
\text { C, Fa, L, Min, } \\
\text { Med, Mel }\end{array}$ \\
\hline & $\begin{array}{l}\text { Cryptocarya aschersoniana Mez } \\
\text { Endlicheria paniculata (Spreng.) J. F. Macbr. }\end{array}$ & $\begin{array}{l}\text { Canela-de-porco } \\
\text { Canela-do-brejo }\end{array}$ & $\begin{array}{l}\text { SI } \\
\text { SI }\end{array}$ & Fa; Mex; Min \\
\hline Lauraceae & $\begin{array}{l}\text { Nectandra megapotamica (Spreng.) Mez } \\
\text { Ocotea corymbosa (Meissn.) Mez } \\
\text { Ocotea lanceolata Nees. }\end{array}$ & $\begin{array}{l}\text { Canela-imbuia } \\
\text { Canela-corvo } \\
\text { Canela-amarela }\end{array}$ & $\begin{array}{l}\text { SI } \\
\text { SI } \\
\text { SI }\end{array}$ & $\begin{array}{l}\text { Fa; Min } \\
\text { Min; Or } \\
\text { Fa; Min }\end{array}$ \\
\hline Fabaceae- & Peltophorum dubium (Spreng.) Taub. & Canafístula & SI & Fe; Min \\
\hline Caesalpinoidea & Pterogyne nitens Tul. & Amendoim & SI & $\begin{array}{l}\text { Mem; Min } \\
\text { Artes; Fer; }\end{array}$ \\
\hline $\begin{array}{l}\text { Fabaceae- } \\
\text { Mimosoidea }\end{array}$ & $\begin{array}{l}\text { Albizia hasslerii (Chodat) Burkart } \\
\text { Parapiptadenia rigida (Benth.) Bren. }\end{array}$ & $\begin{array}{l}\text { Farinha-seca } \\
\text { Gurucaia }\end{array}$ & $\begin{array}{l}\text { SI } \\
\text { SI }\end{array}$ & $\begin{array}{l}\text { Min } \\
\text { C; L; Med; } \\
\text { Mel; Mem; } \\
\quad \text { Mex }\end{array}$ \\
\hline $\begin{array}{l}\text { Fabaceae- } \\
\text { Faboidea }\end{array}$ & Lonchocarpus muehlbergianus Hassler & Feijão-cru & SI & L; Fer; Min \\
\hline Meliaceae & Melia azedarach L. *exótica & Cinamomo & & Mel \\
\hline Monimiaceae & Siparuna apiosyce (Mart.) A. DC. & & & Med \\
\hline Myrtaceae & $\begin{array}{l}\text { Eugenia uniflora } \text { L. } \\
\text { Psidium guajava } \text { L.*exótica } \\
\text { Syzygium cumini } \text { (L.) Skeels *exótica }\end{array}$ & $\begin{array}{l}\text { Pitanga } \\
\text { Goiabeira } \\
\text { Jambolão }\end{array}$ & SI & $\begin{array}{c}\mathrm{Al} ; \mathrm{Fa} ; \\
\text { Fer; Mel } \\
\text { Al; Fa; } \\
\text { Fer;Mex } \\
\mathrm{Al} ; \mathrm{Fa} ; \mathrm{Med}\end{array}$ \\
\hline Arecaceae & Acrocomia aculeata (Jacq.) Lodd. & Macaúba & SI & $\mathrm{Al} ; \mathrm{Fi} ; \mathrm{Ol} ; \mathrm{Or}$ \\
\hline
\end{tabular}

FLORESTA, Curitiba, PR, v. 41, n. 2, p. 377-386, abr./jun. 2011. 


\begin{tabular}{|c|c|c|c|c|}
\hline Piperaceae & Piper glabratum Kunth & & SI & \\
\hline Rubiaceae & Randia ferox DC. & Limão-do-mato & SI & \\
\hline Rutaceae & $\begin{array}{l}\text { Citrus limonia Osbek *exótica } \\
\text { Citrus reticulata } \text { Blanco *exótica }\end{array}$ & Mexerica & & $\mathrm{Al} ; \mathrm{Fa}$ \\
\hline Sapindaceae & $\begin{array}{l}\text { Allophylus edulis (St.-Hil.) Radlk } \\
\text { Matayba elaeagnoides Radlk }\end{array}$ & $\begin{array}{l}\text { Vacum } \\
\text { Miguel-pintado }\end{array}$ & $\begin{array}{l}\text { SI } \\
\text { SI }\end{array}$ & $\begin{array}{l}\mathrm{C} ; \mathrm{Fa} ; \mathrm{L} ; \mathrm{Mex} \\
\mathrm{C} ; \mathrm{Fa} ; \mathrm{L} ; \mathrm{Min}\end{array}$ \\
\hline Sapotaceae & $\begin{array}{l}\text { Chrysophyllum gonocarpum (Mart. \& Eichl.) } \\
\text { Engl. }\end{array}$ & Aguaí & SI/ST & $\begin{array}{l}\text { Artes; Fer; } \\
\text { Min }\end{array}$ \\
\hline Tiliaceae & Luehea divaricata Mart. & Açoita-cavalo & SI & $\begin{array}{l}\text { Artes; Fer; } \\
\text { Mel; Min }\end{array}$ \\
\hline Ulmaceae & Trema micrantha (L.) Blume & Crindiúva & $\mathrm{P}$ & $\begin{array}{l}\text { C; L; Fa; Mel; } \\
\text { Min }\end{array}$ \\
\hline
\end{tabular}

${ }^{1}$ Baseado em Carpanezzi; Carpanezzi, 2006; Carvalho, 2006.

Legenda de usos: Al-alimentação; Artes-artesanato; C-carvão; Fa-atrativa de fauna; Fer-construção de ferramentas; Fi-produção de fibras; L-lenha; Med-medicinal; Mel-melífera; Mem-madeira para embarcações; Mex-madeira para uso externo; Min-madeira para uso interno; Ol-oleaginosa; Or-ornamental.

Observou-se ainda a presença de um grande número de espécies produtoras de frutos atrativos da fauna (Tabela 2), cuja importância é fundamental para a dispersão e introdução de novas espécies nos processos de restauração local e regional, além de espécies com potencial medicinal, produtoras de fibras e oleaginosas.

\section{CONCLUSÕES}

- Com relação ao que diz respeito às áreas de Reserva Legal, os resultados deste trabalho mostraram que Corymbia citriodora pode ser utilizada como espécie facilitadora para a regeneração natural de espécies nativas, as quais poderão ter melhor desenvolvimento com desbastes sistemáticos e seletivos. Apesar da consideração de que a espécie pode criar no solo condições desfavoráveis por efeitos alelopáticos (LIMA, 1996), a espécie não possui caráter invasor, além do que, pelas características da cultura do eucalipto, há pouca ou nenhuma aplicação de pesticidas, o que deve contribuir na capacidade de regeneração natural da vegetação nativa.

- Os resultados também contribuem para demonstrar a possibilidade do consórcio de espécies nativas com eucaliptos, como maneira de viabilizar a diversificação de renda para o agricultor a partir de produção de madeira e de produtos não madeiráveis. Esse consórcio pode ser obtido realizando-se o plantio concomitante de nativas e eucalipto, ou na forma de plantio de nativas em áreas com o eucalipto já estabelecido, e/ou condução da regeneração natural/floresta secundária também em áreas de eucalipto existente sob a forma de rebrotas, como no caso aqui apresentado.

- Após a verificação do potencial de regeneração e recomposição da vegetação natural para fins de formação da Reserva Legal, a próxima etapa para estudo deverá compor o tratamento dos dados em classes de tamanho, o reconhecimento detalhado dos solos e o acompanhamento da dinâmica da regeneração, a fim de propor medidas para o manejo da vegetação, nativa e exótica.

\section{AGRADECIMENTOS}

Davi Gobor (IAP), Erni Lemberger (EMATER), Gracie Abad Maximiano (SEMA), João Carlos de Freitas (EMATER), Luís Cláudio Maranhão Froufe (EMBRAPA Florestas), Luiz Marcos Feitosa dos Santos (EMATER) e Paulo Ernani Ramalho Carvalho (EMBRAPA Florestas), pelo auxílio no inventário da floresta e na identificação das espécies.

\section{REFERÊNCIAS}

ÁVILA, A. L. de; ARAÚJO, M. M.; ALMEIDA, C. M. de; LIPERT, D. B.; LONGHI, R. Regeneração natural em um sub-bosque de Eucalyptus camaldulensis Dehnh., Santa Maria, RS. Revista Brasileira de Biociências, Porto Alegre, v. 5, n. 2, p. 696 - 698, 2007. 
CARPANEZZI, A. A.; CARPANEZZI, O. T. B. Espécies nativas recomendadas para a recuperação ambiental no estado do Paraná, em solos não degradados. Colombo: Embrapa Florestas, 2006. 57 p. (Embrapa Florestas. Documentos, 136).

CARVALHO, P. E. R. Espécies arbóreas brasileiras. Brasília: Embrapa Informação Tecnológica; Colombo: Embrapa Florestas, 2006, v. 2, 627 p.

CRONQUIST, A. An integrated system of classification of flowering plants. New York: Columbia University, 1981. $1262 \mathrm{p}$.

FERREIRA, W. C.; FERREIRA, M. J.; MARTINS, J. C. Regeneração natural de espécies arbustivoarbóreas no sub-bosque de Eucalyptus grandis em Mata Ciliar, no Município de Lavras, MG. Revista Brasileira de Biociências, Porto Alegre, v. 5, n. 1, p. 579 - 581. 2007.

GELDENHUIS, C. J. Native forest regeneration in pine and eucalypt plantations in Northern Province, South Africa. Forest Ecology and Management, Amsterdan, v. 99, n. 1, p. 110 - 115, 1997.

FEYERA, S.; BECK, E.; LÜTTGE, U. Exotic trees as nurse-trees for the regeneration of tropical forests. Trees, v. 16, n. 4-5, p. 245 - 249, 2002.

FIDALSKI, J. Sistema de terraceamento agrícola proposto para o noroeste do Paraná. Acta Scientiarum, Maringá, v. 20, n. 3, p. 313 - 316, 1998.

INSTITUTO AGRONÔMICO DO PARANÁ (IAPAR). Cartas climáticas do Paraná (edição 2000). Disponível em <http://200.201.27.14/Sma/Cartas_Climaticas/Cartas_Climaticas.html>. Acesso em: 07/01/2009.

INSTITUTO BRASILEIRO DE GEOGRAFIA E ESTATÍSTICA (IBGE). VELOSO, H. P.; RANGEL FILHO, A. L. R.; LIMA, J. C. A. Classificação da vegetação brasileira, adaptada a um sistema universal. Rio de Janeiro. 123 p. 1991.

INSTITUTO BRASILEIRO DE GEOGRAFIA E ESTATÍSTICA (IBGE). Mapa de vegetação 2004. Disponível em <fttp://geoftp.ibge.gov.br/mapas/tematicos/mapas_murais/vegetacao.pdf>. Acesso em: 07/01/2009.

INSTITUTO PARANAENSE DE DESENVOLVIMENTO ECONÔMICO E SOCIAL (IPARDES). Leituras regionais: Mesorregião Geográfica Noroeste Paranaense. Instituto Paranaense de Desenvolvimento Econômico e Social. Curitiba: IPARDES: BRDE, 2004. 141 p.

LIMA, W. P. Impacto ambiental do eucalipto. São Paulo: Editora da USP. 1996.

MUZILLI, O. Plano integrado para o manejo e conservação do solo em microbacia hidrográfica piloto. A experiência do Paraná na região do Arenito Caiuá. In: CASTRO FILHO, C. MUZILLI, O. (ed.). Manejo Integrado de solos em microbacias hidrográficas. Londrina, IAPAR; 1996. p. 97 - 119.

PARANÁ. Secretaria de Estado de Meio Ambiente. Lista Vermelha de plantas ameaçadas de extinção no Estado do Paraná. Curitiba: SEMA/GTZ, 1995. 139 p.

SAPORETTI JÚNIOR, A. W.; MEIRA NETO, J. A. A.; ALMADO, R. Fitossociologia de sub-bosque de cerrado em talhão de Eucalyptus grandis W. Hill ex Maiden no município de Bom Despacho, MG. Árvore, Viçosa, v. 27, n. 6, p. 905 - 910, 2003.

SARTORI, M. S.; POGGIANI, F.; ENGEL, V. L. Regeneração da vegetação arbórea nativa no subbosque de um povoamento de Eucalyptus saligna Smith. localizado no Estado de São Paulo. Scientia Forestalis, Piracicaba, n. 62, p. 86 - 103, 2002.

SCHNEIDER, M. F. Consequências da acumulação de folhas secas na plantação de eucalipto em Zitundo, Distrito de Matutuíne. Boletim de Investigação Florestal, Maputo, n. 3, p. 37 - 42, 2003.

SILVA JÚNIOR, M. C.; SCARANO, F. R.; CARDEL, F. S. Regeneration of an Atlantic Forest formation in the understorey of a Eucaliptus grandis plantation in south-eastern Brazil. Journal of Tropical Ecology, Aberdeen, v. 11, p. 147 - 152. 1995. 
FLORESTA, Curitiba, PR, v. 41, n. 2, p. 377-386, abr./jun. 2011

Oliveira, E. B. de; Sousa, L. P. de; Radomski, M. I. 